\title{
RETRACTED ARTICLE: Studies of Microtexture and Its Effect on Tensile and High-Cycle Fatigue Properties of Laser-Powder-Deposited INCONEL 718
}

\author{
HUAN QI, MAGDI AZER, and ANDREW DEAL
}

DOI: $10.1007 / \mathrm{s} 11661-012-1509-6$

(C) The Minerals, Metals \& Materials Society and ASM International 2013

THIS paper is being retracted because the authors did not get clearance to publish the technical explanations as described in the paper.

HUAN QI, Assistant Professor, is with the University of Michigan-Shanghai Jiaotong University Joint Institute, Shanghai 200240, P.R. China. Contact e-mail: huan.qi@sjtu.edu.cn MAGDI AZER, Lab Manager, and ANDREW DEAL, Senior Scientist, are with the General Electric Global Research Center, Niskayuna, New York, NY 12309.

Manuscript submitted May 16, 2012. 